\title{
TRANSIENT INVERTED T WAVES AFTER PAROXYSMAL TACHYCARDIA
}

\author{
BY \\ GEORGE M. CURRIE \\ From the Kilmarnock Infirmary \\ Received July 21, 1942
}

Graybiel and White (1934) have stressed that care must be taken in the diagnosis of serious heart disease when inverted $T_{1}$ or $T_{2}$ waves are the only abnormal finding, and that this inversion is not invariably associated with organic disease. They cited two cases of paroxysmal tachycardia in young robust adults, one followed by inverted $T_{1}$ and the other by inverted $T_{2}$ and $T_{3}$ waves; there was no sign of organic disease and there was a gradual return to a normal cardiogram. Campbell and Elliot (1939) record two cases of ventricular tachycardia that gave transient changes simulating coronary thrombosis; one of these gave a history of diphtheria and the other was of long standing and had been suffering from increasing dyspnœa during the intervals between attacks; both died suddenly at a later date. These cases show that the general condition must be given prime consideration in forming a prognosis.

It is generally recognized that the commonest causes of inversion of $T$ waves are coronary thrombosis, myocardial disease due to toxæmia or hypertension, large doses of digitalis, the physiological effect of taking cold drinks, and the position of the heart. White (1941) has recently shown that change of posture may bring about an inversion of $\mathrm{T}$ waves especially in persons of the neurocirculatory asthenic type.

\section{Present CASE}

A girl, aged 13 years, was admitted to Kilmarnock Infirmary with paroxysmal tachycardia that had already lasted 24 hours. The attack stopped spontaneously after a total duration of 36 hours; it was unaffected by any of the usual procedures to terminate it.

Previous History. An only child, nervous and of nervous parentage; whooping cough at 2 years but no sequelæ; no other ailments except chickenpox, until her first attack of tachycardia three years previous to the present one, when she got a fright while on a swing; six attacks since then; her mother stated that these seemed to come on after an attack of flatulent indigestion but with no actual warning, the first thing the child felt being a " thumping" in her chest; the duration varied from 2 to 24 hours and each attack stopped suddenly, leaving the patient well but weak for some days. 
Examination. On admission, pulse rate 214, respirations 26, and temperature normal. During the paroxysm there was an obvious impulse over the cardiac area; there was no enlargement of the heart; a systolic murmur most marked just to the left of the sternum; no signs of pulmonary congestion or of enlargement of the liver or spleen; but some flatulent gastric distention: a cardiogram confirmed the diagnosis of paroxysmal tachycardia, most likely of ventricular origin: radiological report, no abnormality either of heart or lungs. The next morning her pulse rate was 96 and the blood pressure was $112 / 82$; she was comfortable but apprehensive; the cardiogram showed lowered S-T and inverted $T_{2}$ and $T_{3}$; on the next day it was the same; four days after the attack there was also some slight inversion of $T_{1}$; thereafter there was steady improve-

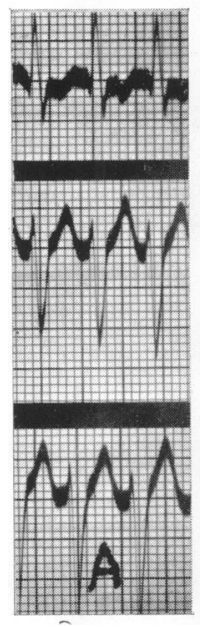

(A) During attack.
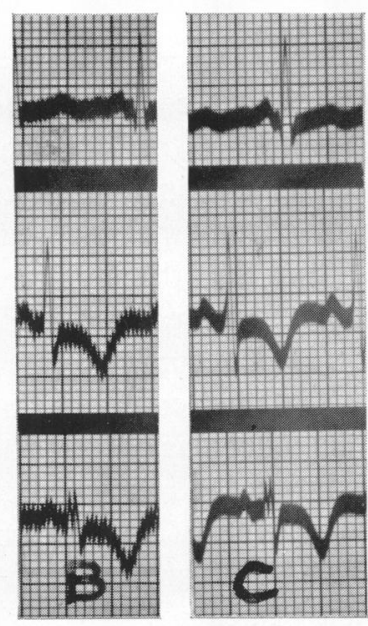
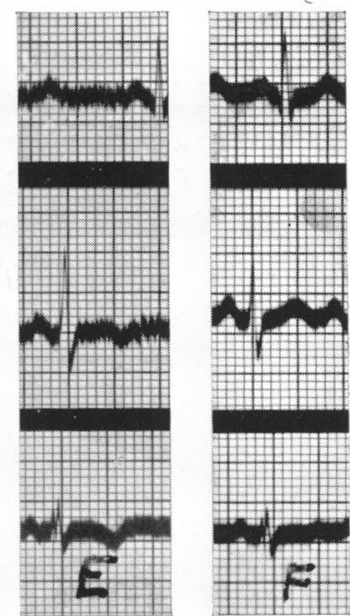

FIG. 1.-Attack on $31 / 10 / 39$.

$\begin{array}{lll}\text { (B) Following day. } & \text { (C) } 2 \text { days after. }\end{array}$

$\begin{array}{ll}\text { (E) } 13 \text { days after. } & \text { (F) } 30 \text { days after. }\end{array}$

(D) 4 days after.

ment till on 30/11/39 it was normal (Fig. 1). The patient was kept resting in bed for eight days and was dismissed at the end of two weeks.

On 4/6/40 re-examination showed a similar normal cardiogram; she had kept fairly well except for a morbidly introspective mentality for a girl of her years; she had been kept on a simple carminative mixture and small doses of phenobarbital.

On $28 / 8 / 40$ she was seen at the start of another attack and a cardiogram taken within an hour was similar in form to the first but the $\mathrm{T}$ waves were higher; it should be remembered that the former had been taken 24 hours after the onset. This attack lasted three hours. The records in this case (Fig. 2) show that on $1 / 9 / 40 \mathrm{~T}_{2}$ and $\mathrm{T}_{3}$ were inverted but the $\mathrm{S}-\mathrm{T}$ interval was unaffected; on $11 / 9 / 40 T_{2}$ was isoelectric and $T_{3}$ only slightly inverted; on 25/9/40 there was a return to normal.

On 20/6/41 the cardiogram was normal; in the interval there had been no further attacks and the patient had much improved generally; she had been encouraged to lead a normal life; she mixed with other girls, and at the same 


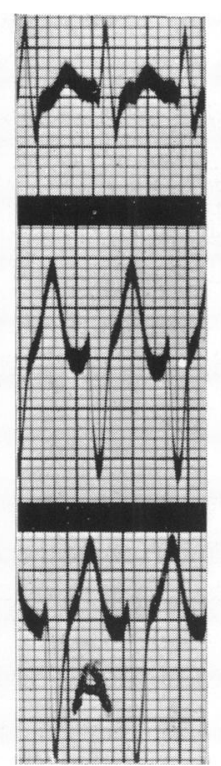

(A) During attack.
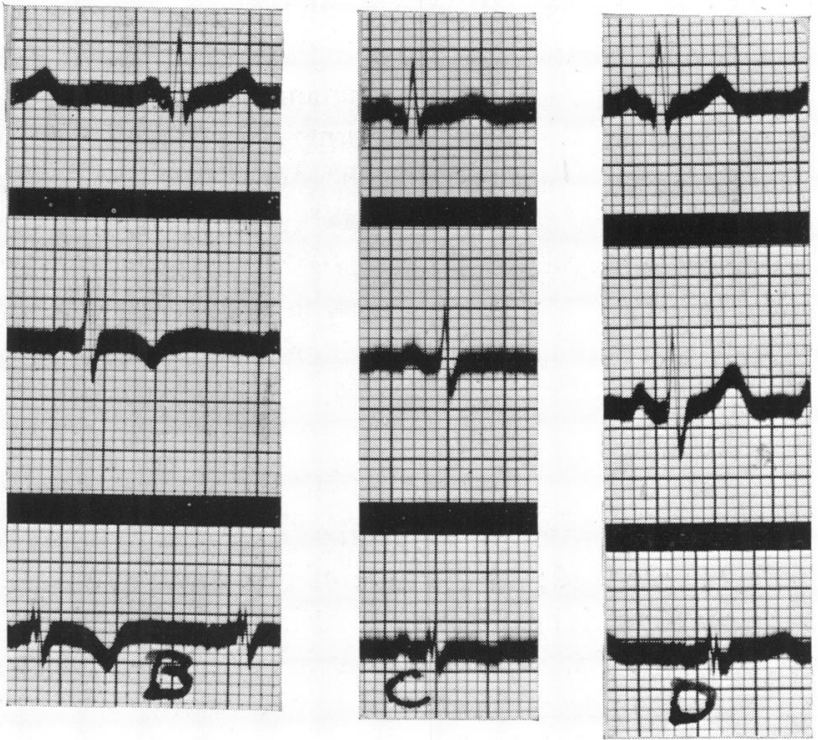

FIG. 2.-Attack on $28 / 8 / 40$.
(B) 4 days later.
(C) 14 days later.
(D) 28 days later.

time her mother had been prevailed upon not to shelter her only child so much; she was now working in an office.

At the present time (April, 1942) she is well and has had no return of the tachycardia since August, 1940; her pulse rate and blood pressure are normal, as is also the cardiac condition; her nervousness is decidedly less.

\section{Discussion}

When this patient first came under observation she was classed as neurocirculatory asthenia on account of her general state and the absence of organic disease and of any history of disease leading to cardiac complications; she was easily tired and excited, and had palpitation and dyspnœa with slight exertion and excitement, and slight tachycardia even when resting.

The degree of inversion of the $\mathrm{T}$ waves and the disturbance of the S-T interval appeared less after the second attack which was only 3 hours duration as against 36 hours in the first; this would seem to indicate that the duration and hence the degree of strain on the myocardium affect the amount of temporary change in the cardiogram; this is important when one comes to consider the cause of the inversion, and lends weight to the theory that it is due to overstrain of the myocardium.

The primary fact that emerges is that abnormalities simulating coronary thrombosis have arisen apart from detectable organic disease; if the paroxysmal condition had not been confirmed at the time of the attack, the subsequent records might have raised suspicion of serious heart disease. The second series confirmed the transient nature of the cardiographic abnormality. The case 
has not been reported earlier in order that a sufficient time should elapse to rule out the development of cardiac complications. In view of the different endings in the cases quoted and the present one-fatal in those of Campbell and Elliot, apparent recovery in those of Graybiel and White and the present case-the clinical findings should be taken into consideration, when it is seen that a bad prognosis was probable in the fatal cases in view of the presence of organic lesion or toxic history, while in the other three cases there was no discoverable organic lesion. This is obviously another instance of a condition where negative $T$ waves may not have the serious prognostic import usually attributed to them.

\section{SUMMARY}

A case of recurrent paroxysmal tachycardia in a girl with neuro-circulatory asthenia is described; at the time of first observation she was 13 years of age and is now 16; serial cardiograms during and after each attack showed transient inversion of the $T$ waves and a lowering of the $S-T$ interval in one series; there was a return to normal in each case in a month; the degree of the inversion is probably affected by the duration of the attack. The relative importance of the clinical over the cardiographic findings in giving a prognosis in such cases is stressed, and a possible cause of the inversion is put forward.

Addendum. Since this article was written Campbell (1942) has reported three cases in addition to those already referred to (Campbell and Elliot, 1939); these additional cases were of the clinically " benign " type, and the transient alteration in the $\mathrm{T}$ waves was considered not to "indicate any organic disease but to be a completely reversible process indicating some degree of exhaustion or strain of the heart muscle," a conclusion agreeing with that already formed regarding the present case.

\section{REFERENCES}

Campbell, M., and Elliot, G. A. (1939). Brit. Heart J., 1, 123.

- (1942). Ibid., 4, 49.

Graybiel, A., and White, P. D. (1934). Amer. Heart J., 10, 345.

White, P. D., Chamberlain, F. L., and Graybiel, A. (1941). Brit. Heart J., 3, 233. 